\title{
Sistema climático e corpo humano: conceitos da física de sistemas complexos para a sala de aula
}

\author{
Climatic and human body system: concepts of the physics of complex systems to the classroom
}

\author{
Diogo Amaral de Magalhães ${ }^{*}$, Frederico Firmo de Souza Cruz ${ }^{2}$ \\ ${ }^{1}$ Instituto Federal Catarinense, São Francisco do Sul, SC, Brasil. \\ ${ }^{2}$ Universidade Federal de Santa Catarina, Florianópolis, SC, Brasil.
}

Recebido em 31 de outubro de 2020. Revisado em 12 de dezembro de 2020. Aceito em 14 de dezembro de 2020.

O objetivo deste artigo é subsidiar reflexões e abordagens didáticas acerca de conceitos da complexidade de sistemas físicos. Em particular, discute-se a complexidade do sistema climático no contexto do aquecimento global a partir de uma analogia com o corpo humano e com base no conceito de temperatura. São apresentadas falsas críticas à ideia de temperatura global e possíveis respostas a elas. Após o sistema climático ser caracterizado como complexo, são abordados aspectos dessa complexidade contemplados nos modelos climáticos. Por fim, utiliza-se o corpo humano como modelo de sistema complexo para discutir a complexidade do sistema climático. Afinal, por que a Terra está doente?

Palavras-chave: Complexidade, Modelos Climáticos, Aquecimento Global, Temperatura Global, Ensino da Física.

The purpose of this article is to support reflections and didactic approaches concerning concepts of the complexity of physical systems. In particular, the complexity of the climate system in the context of global warming is discussed from an analogy with the human body and based on the concept of temperature. False criticisms of the idea of global temperature and possible responses to them are presented. After the climate system is characterized as complex, aspects of this complexity covered in climate models are addressed. Finally, the human body is used as a model of a complex system to discuss the complexity of the climate system. After all, why is the Earth sick?

Keywords: Complexity, Climate Models, Global Warming, Global Temperature, Physics Teaching.

\section{Introdução}

Em livro que aborda várias controvérsias científicas, Naomi Oreskes e Erik Conway discutem a história de um grupos de cientistas gabaritados que lutam contra as evidências científicas e disseminam confusão acerca de diversas questões cruciais atuais: os "mercadores da dúvida" 1. A análise dos autores se concentra no que chamam de "estratégia do tabaco", a qual é utilizada pelos mercadores para atacar a ciência e os cientistas, criando dúvidas sobre temas que afetam diretamente as nossas vidas e o nosso planeta, como a chuva ácida, o tabaco, os CFCs e a camada de ozônio e o aquecimento global. No caso do tabaco, eles transformaram as evidências sobre os seus efeitos cancerígenos em incertezas científicas. Dessa forma, evitaram ações legais que poderiam impactar economicamente as empresas do ramo.

No que diz respeito ao aquecimento global, os mercadores da dúvida iniciaram sua atuação questionando as conclusões do relatório de 1995 do IPCC (Painel Intergovernamental das Mudanças Climáticas), a maior

\footnotetext{
* Endereço de correspondência: diogo.magalhaes@ifc.edu.br
}

autoridade mundial em assuntos do clima, criada em 1988 pela WMO (Organização Mundial de Saúde) e pelo Programa de Meio Ambiente da ONU. O primeiro foco da operação dos mercadores foi a "discernibilidade" da ação humana sobre as mudanças climáticas; em particular, eles atacaram a figura de Ben Santer, cientista de reputação impecável e responsável pelo capítulo do relatório que apresentou evidências acerca do impacto dos gases do efeito estufa sobre o aquecimento global, conforme explicam Oreskes e Conway [1. Santer foi acusado de fraude por alterações na primeira versão do relatório que objetivariam enganar políticos e população; no entanto, tratavam-se de ajustes e revisões que foram sugeridos por outros cientistas.

Primeiramente, os mercadores negaram a realidade do aquecimento global. Em seguida, afirmaram que ele era fruto de variações naturais. Por fim, defenderam que a eventual existência do aquecimento global e a respectiva responsabilidade humana não eram importantes, uma vez que nós poderíamos nos adaptar a isso 11. O "modus operandi" dos mercadores, portanto, sempre foi manter as controvérsias vivas. No caso do clima, questionam o consenso científico acerca do impacto humano sobre as mudanças climáticas, atribuindo às causas naturais 
o peso maior sobre o aquecimento global, além de se argumentar que a Terra já teve épocas mais quentes e que a humanidade se adaptaria.

Nesse contexto, a ideia de temperatura global do planeta é crucial na controvérsia, uma vez que a Terra é um sistema complexo e aberto para o qual não se define um estado de equilíbrio térmico com o meio externo. Assim, a questão da interpolação das medidas de temperatura dos modelos climáticos (onde não há bases meteorológicas para coleta de dados) e o tratamento estatístico das medidas de temperatura (de um sistema fora do equilíbrio térmico), por exemplo, evidenciam aspectos das complexidades do clima e, consequentemente, dos modelos climáticos. Os mercadores da dúvida, por sua vez, se utilizam dessa natureza complexa para desacreditar o conhecimento científico que se tem sobre o clima 1

No que diz respeito às potencialidades para o ensino da física, o conceito de temperatura global problematiza significativa parte dessa complexidade, tal que uma discussão crítica sobre a física concernente à ideia de temperatura global visa preencher algumas lacunas dos trabalhos produzidos pela comunidade da área de ensino de física. Por um lado, segundo a revisão de Reis e Silva [2], aspectos políticos e econômicos são os mais enfocados nas dissertações e teses da área de Educação Ambiental, evidenciando poucas discussões com enfoque nos conceitos e conteúdos da ciência. Por outro lado, Pina, Silva e Oliveira Jr. 3], Magalhães [4] e Reis, Silva e Figueiredo [5] apresentaram aspectos e abordagens para o ensino crítico da física do clima. No entanto, as naturezas dos modelos climáticos e, em especial, da ideia de temperatura global e das anomalias de temperatura podem ser mais aprofundadas e direcionadas para a sala de aula com a intenção de evidenciar parte da complexidade do clima. Para isso, utilizamos um outro sistema complexo, aberto e fora do equilíbrio termodinâmico, o corpo humano, como modelo para discutir noções dessa complexidade.

Na seção 22 apresentamos falsas críticas à ideia de temperatura global e possíveis respostas a elas. Em seguida (seção 3), caracterizamos o sistema climático como complexo. Na seção 4, abordamos, de forma introdutória, aspectos dessa complexidade que são contemplados nos modelos climáticos. Após analisarmos o corpo humano como um sistema complexo (seção 5), o propomos como modelo didático análogo para discutir noções da complexidade do sistema climático (seção 6). Por fim, analisamos contribuições e potencialidades para o ensino de física, com foco na atuação do professor em sala de aula (seção 7).

\footnotetext{
${ }^{1}$ Nossa concepção de complexidade diz respeito à natureza físicoquímica e às leis que regem o sistema físico em questão, o clima, cuja definição é dada de maneira orgânica ao longo do texto, especialmente na seção 3
}

\section{Temperatura Global}

A Terra é um sistema que está em constante troca de energia com o espaço. Ela recebe energia solar na forma de ondas eletromagnéticas, especialmente luz visível e radiação ultravioleta (ondas longas), a qual é espalhada e refletida pelas nuvens e aerossóis ou absorvida pela atmosfera. Assim, a energia restante é refletida ou absorvida pela superfície da Terra, sendo transformada em calor latente, calor sensível, energia potencial e energia cinética, que são responsáveis por processos como a fotossíntese, a evaporação da água, o derretimento de gelo e o aquecimento do sistema terrestre. Em seguida, a Terra emite radiação infravermelha para o espaço (ondas curtas), sendo uma fração dessa energia resultado de processos naturais e outra em virtude das ações do homem.

As diferentes formas de energia são redistribuídas através de processos físicos na atmosfera, nos mares, na litosfera e na biosfera. A sua totalidade contribui, de forma não linear, para que o planeta alcance um estado de equilíbrio dinâmico caracterizado por uma temperatura global que permitiu, ao longo da história, o estabelecimento e manutenção da vida. Portanto, por ser um sistema dinâmico, aberto e fora do equilíbrio térmico, algumas críticas, ao estilo mercadores da dúvida, são lançadas sobre a atribuição de um único número para o aquecimento da Terra: $0,85^{\circ} \mathrm{C}$, de acordo com o IPCC [6].

Em polêmico artigo publicado em um periódico especializado em termodinâmica fora do equilíbrio, Essex, Mckitrick e Andressen [7] se propuseram a responder à questão, que dá nome ao seu trabalho: "Existe temperatura global?". A resposta dos autores é categórica: "Não existe temperatura global". Seu argumento central é a impossibilidade de se construir uma média de temperaturas sem que haja princípios físicos que baseiem tal escolha estatística:

\begin{abstract}
"Embora seja sempre possível construir estatísticas para qualquer conjunto de dados locais de temperatura, uma gama infinita de tais estatísticas é matematicamente permissível se os princípios físicos não fornecem uma base explícita para a escolha entre elas. Regras estatísticas distintas e igualmente válidas podem e mostram tendências opostas quando aplicadas aos resultados de cálculos de modelos físicos e dados reais na atmosfera. Um determinado campo de temperatura pode ser interpretado como em 'aquecimento' e 'resfriamento' simultaneamente, tornando fisicamente mal colocado o conceito de aquecimento no contexto da questão do aquecimento global" [7] ${ }^{2}$
\end{abstract}

\footnotetext{
2 Tradução nossa.
} 
O argumento de Essex, Mckitrick e Andressen 7 é que diferentes regras para a construção de médias espaciais de temperatura podem levar a conclusões contraditórias, pois é impossível se definir uma temperatura termodinâmica para um sistema como a Terra. Ou seja, um sistema constituído por dois corpos a temperaturas iniciais diferentes, dependendo de qual estatística é escolhida para tratar as suas temperaturas, pode se aquecer ou se resfriar com o passar do tempo. Portanto, sem critérios físicos e pragmáticos para a escolha da média "não há nenhuma base para se concluir que a atmosfera, como um todo, esteja se aquecendo ou se resfriando", segundo os autores.

Ademais, Essex, Mckitrick e Andressen [7] criticam o que chamam de "termodinâmica a distância". Devido à inviabilidade de se constituir bases de coletas de dados para medições de dados climáticos em todas as regiões do planeta, os cientistas precisam incorporar interpolações em seus modelos para esses casos. Assim, argumentam que uma média espacial global de temperaturas não pode ser utilizada para embasar estimativas sobre condições climáticas locais e vice-versa, o que faria dela uma ideia inadequada e sem significado físico.

Os autores desse controverso artigo questionam a incompletude dos dados meteorológicos, as interpolações nas medidas de temperatura para muitas regiões e os modelos com seus diferentes pesos utilizados para a obtenção das médias. No entanto, não nos parece que eles levem em conta a complexidade do sistema e a sua não linearidade, sugerindo um tratamento reducionista da ciência desse sistema. Em outras palavras, eles suscitam ataques sobre a natureza metodológica, principalmente, e epistêmica dos modelos climáticos e suas interpolações, considerando fatores espaciais, temporais e instrumentais para os registros dos dados de temperatura. Entretanto, complexidades e incompletudes nunca impediram os cientistas de obterem conclusões e se posicionarem cientificamente em situações como essa, pois existem conhecimentos historicamente adquiridos e validados por pares que fundamentam suas tomadas de decisão, bem como da sociedade.

Em suma, observamos que a linha crítica de Essex, Mckitrick e Andressen [7] tem a mesma perspectiva da estratégia do tabaco, ao estilo mercadores da dúvida. Eles se utilizam de conceitos da ciência, em particular da termodinâmica clássica do equilíbrio, evocando diferentes médias para o estudo de dois corpos isolados que se equilibram a temperatura ambiente para questionar a utilização do conceito de temperatura para um sistema fora do equilíbrio. Percebemos que há uma distorção intencional no uso de ideias científicas que cria uma conclusão que não corresponde ao sistema climático. Ou seja, não faz sentido falar na variação da temperatura global (aquecimento/resfriamento) a partir da variação

\footnotetext{
3 Segundo os autores, a física do sistema climático deveria dizer que média considerar, como quando calculamos resistências equivalentes para resistores em série e em paralelo, por exemplo.
}

da temperatura média do processo de equilibração de dois corpos isolados com um meio. 4

De encontro às críticas de Essex e seus colaboradores, lembremos que existem diversas maneiras de se inferir a temperatura de um sistema a partir de leis físicas bem compreendidas. A temperatura de um sistema como o nosso planeta não deixa de ser uma quantidade com significado físico porque ele se encontra fora do equilíbrio térmico. De fato, a lei de Stefan-Boltzmann nos permite estimar a temperatura da superfície de qualquer corpo que irradia, como é o caso do Sol e da Terra, por meio da equação:

$$
R=\sigma T^{4}
$$

onde $R$ é a sua radiância espectral, ou energia emitida por unidade de tempo e área $\left(\mathrm{W} / \mathrm{m}^{2}\right), \sigma$ é a constante de Stefan-Boltzmann e $T$ é a temperatura absoluta da superfície do corpo.

Conforme já mencionamos, a Terra é um sistema aberto em constante troca de energia, que interage com o universo exterior através da emissão e da absorção de radiação. O fluxo de calor é contínuo e é difícil o estabelecimento do equilíbrio térmico. No entanto, se em uma dada região o fluxo do calor que entra e o que sai são o mesmo, pode-se falar, ao menos durante um certo período, em equilíbrio térmico, isto é, em temperatura, como nos ensina a lei zero da termodinâmica.

Portanto, a temperatura de sistemas abertos depende do tempo de medida e da sua estabilização, mesmo que seja em apenas um certo período. Detectores de radiação podem ser colocados em aeronaves ou satélites de tal forma que é possível fazer medidas de temperaturas de regiões com grande área territorial. Entretanto, quando se pensa na superfície total da Terra e na imensa movimentação das massas atmosféricas, estamos diante de um problema extremamente complexo e sujeito a muitas incertezas.

Passemos, então, a analisar alguns desses aspectos, buscando identificar mecanismos de estabilização de temperatura da Terra e compreender algumas especificidades dinâmicas dos modelos climáticos.

\section{A Natureza Complexa do Sistema Climático}

Conforme discutimos, críticas ao conceito de temperatura global são feitas sem que se leve em conta a

\footnotetext{
4 Embora a temperatura final de um sistema isolado constituído por dois corpos em contato não seja, em princípio, uma média aritmética de suas temperaturas iniciais, ela é uma média ponderada, pois depende, como sabemos, da massa e do calor específico de cada um deles; a temperatura final é a temperatura de equilíbrio térmico. Se simplesmente considerarmos as temperaturas iniciais de ambos e calcularmos médias diferentes (aritmética, geométrica, quadrática, etc.), teremos resultados distintos. Considerando a lei de resfriamento/aquecimento de Newton e a temperatura final como a de equilíbrio (temperatura ambiente), teremos situações "contraditórias" de aquecimento ou resfriamento, as quais dependem dos valores considerados.
} 
complexidade do clima. Ao considerarmos esse aspecto, podemos compreender que a temperatura global da Terra permite identificar uma parcela significativa dessa complexidade. Logo, o entendimento mais abrangente da ideia de temperatura global depende da compreensão que se tem sobre o sistema climático, o que exige que o caracterizemos como um sistema complexo. Dessa forma, esse estudo depende de uma série de outras questões, tais como: O que caracteriza um sistema complexo? O que é o clima? E sistema climático? Que tipo de interações existem entre os componentes do sistema climático e quais suas influências?

Uma definição acerca da ideia de complexidade é dada por Gallagher e Appenzeller [8] um sistema complexo é aquele cujas propriedades não podem ser completamente explicadas pelo entendimento das suas partes constituintes. Em outras palavras, a ciência dos sistemas complexos aborda as maneiras pelas quais os seus componentes mais elementares dão origem ao comportamento coletivo emergente do seu todo. A visão dos autores, como percebemos, afasta a possibilidade de uma explicação estritamente reducionista. Ao mesmo tempo, eles não negam a eventual explicação de algumas de suas propriedades a partir do entendimento das suas partes mais fundamentais.

Por outro lado, a complexidade de um sistema pode ser caracterizada pelas múltiplas interações entre os seus diversos subsistemas [9, 10]. Didaticamente, tais interações podem ser exemplificadas da seguinte maneira: a chuva que cai sobre a Terra contribui para o crescimento das plantas, as quais liberam umidade de volta para a atmosfera. Uma vez lá, o vapor de água forma nuvens, as quais influenciam no próprio crescimento das plantas. Sem nos prolongarmos demasiadamente, ciclos dessa natureza envolvem a física das nuvens e dos oceanos e processos de irradiação atmosférica, bem como os biológicos e químicos, dentre outros subsistemas do sistema climático e suas interações, que implicam efeitos em diferentes escalas temporais e espaciais.

Em particular, destacamos o papel crucial da interação oceano-atmosfera no sistema climático: a regulação do clima. Juntos, oceano e atmosfera atuam no transporte da energia excedente das regiões tropicais do planeta para as regiões polares, onde há uma defasagem de energia. Como a Terra é um sistema que recebe energia solar constantemente, esse processo é permanente. Com alguma intuição sobre o conceito de complexidade, vejamos por que o clima é complexo.

Para Gavin Schmidt [11, pesquisador e diretor do GISS, o clima é um fenômeno de larga escala, fruto de complicadas interações entre sistemas microfísicos e uma descrição estatística das médias de seus elementos e suas variabilidades. A perspectiva do renomado pesquisador está alinhada com as definições sistemáticas do relatório do IPCC [6]: o sistema climático é um sistema altamente complexo, constituído por cinco componentes majoritários: a atmosfera, a hidrosfera, a criosfera, litosfera e a biosfera, bem como as interações entre elas. Tanto a dinâmica interna da Terra, como as forçantes externas, tais como as erupções vulcânicas, as variações solares e as influências do homem, afetam o sistema climático. Por sua vez, o clima é um estado do sistema climático que é caracterizado por uma descrição estatística. Mais especificamente, o relatório estabelece que essa descrição estatística é dada em termos de médias e variabilidades de quantidades como temperatura, precipitação e vento, tal que ela é calculada ao longo de um intervalo de tempo 5

Portanto, o entendimento das mudanças climáticas exige poderosos instrumentos de investigação, os quais devem ser capazes de captar, com a maior precisão possível, a complexidade do sistema climático. Dessa forma, "os modelos climáticos são as principais ferramentas disponíveis para investigar a resposta do sistema climático a várias forçantes, para fazer previsões climáticas em escalas de tempo sazonais a decadais e para fazer projeções do clima futuro no próximo século e além" 12. As características gerais e certas especificidades de alguns desses modelos são abordadas na próxima seção.

\section{A Natureza Complexa nos Modelos Climáticos}

De maneira geral, o desenvolvimento dos modelos climáticos leva em conta quatro aspectos, os quais pretendem captar a complexidade do sistema climático: (i) as observações dos componentes do clima; (ii) os arquivos paleoclimáticos; (iii) os estudos teóricos dos processos climáticos; e (iv) as simulações usando modelos climáticos [6].

Os dados observacionais de temperaturas e outras variáveis existem, em escala global, desde a metade do século XIX, mas, somente a partir de 1950, os dados tornaram-se mais compreensíveis e diversificados. A estimativa das variações da temperatura global na superfície da Terra pode ser feita a partir de medidas diretas por meio de estações meteorológicas distribuídas pelo globo terrestre, por sensoriamento remoto de satélites e outras plataformas, bem como a partir de medidas indiretas de fenômenos correlacionados, como o aumento de volume dos oceanos devido à sua expansão térmica e à variação das massas de gelos nos polos.

Já as reconstruções paleoclimáticas ampliam os registros em centenas de milhões de anos. Segundo Hansen e Sato 13, a história paleoclimática da Terra nos mostra como o clima respondeu às mudanças passadas; essas alterações passam pelos movimentos tectônicos, erupções vulcânicas, variações na composição atmosfera e dos oceanos. Por sua vez, Berger [14, p. 107] explica que "as reconstruções paleoclimáticas nos ajudam a descobrir a variabilidade natural do sistema climático

\footnotetext{
${ }^{5}$ O período usual, como indicado pela WMO, é de 30 anos [6].
} 
ao longo de escalas temporais que vão de anos até centenas de milhares de anos". Juntamente com as observações, as reconstruções paleoclimáticas visam dar uma perspectiva compreensível acerca da variabilidade e das mudanças de larga escala na atmosfera, na criosfera, nos oceanos e na superfície da Terra, considerando como os processos internos naturais e os externos alteram o balanço energético da Terra, impactando sobre a temperatura do planeta. Nesse contexto, as pesquisas sobre os impactos antropogênicos são cruciais.

Os modelos climáticos são, portanto, representações matemáticas do sistema climático e envolvem princípios físicos (e também biológicos e químicos). Devido ao caráter complexo e às diferentes escalas espaciais envolvidas nos diferentes tipos de modelo, as equações matemáticas só podem ser resolvidas numericamente. Utilizando diferentes parametrizações, os modelos têm propósitos específicos e, embora sejam fundamentalmente diferentes, são complementares. Mas, sobretudo, eles contemplam as respostas da atmosfera e dos oceanos à radiação solar, analisando o balanço de energia e a circulação de energia e massa, com foco nas interações entre os seus principais componentes como a atmosfera, a superfície da Terra, os oceanos e as camadas de gelo.

Os Modelos de Circulação Geral Atmosfera-Oceano (AOGCM) buscam entender a dinâmica dos componentes físicos do clima - atmosfera, oceano, superfície e mares de gelo, tomando projeções com bases nas forçantes radiativas relativas às futuras emissões de gases do efeito estufa e aerossóis. Eles são exaustivamente aplicados em predições em escalas sazonais a decenais, quando fatores mais complexos, como os biogeoquímicos, não são críticos. Os AOGCM, em particular, assim como os que focam em regiões específicas, os Modelos Climáticos Regionais (RCM), podem ser rodados em alta resolução.

Os Modelos do Sistema Terrestre (ESM) são mais complexos do que os AOGCM por considerarem ciclos biogeoquímicos, como os do carbono e do enxofre. Já os Modelos do Sistema Terrestre de Complexidade Intermediária (EMIC) buscam incluir componentes de forma idealizada ou em menor resolução do que os
AOGCM e os ESM, tal que os EMIC são aplicados a certas questões científicas, como a compreensão dos mecanismos de feedback climáticos em escalas milenares.

Em suma, conforme buscamos explicitar até aqui, o grau de complexidade contemplada nos modelos varia significativamente, dependendo de mecanismos de feedback e ciclos biogeoquímicos, por exemplo. Por outro lado, os modelos podem ser considerados mais complexos quando levam em conta um número mais alto de componentes ou requerem maior resolução espacial; desse modo, eles possuem um custo computacional maior. Ademais, é imprescindível a avaliação individual e coletiva da performance dos modelos [12]. Em particular, os Projetos de Intercomparação de Modelos Acoplados (CMIP3 e CMIP5) exploram os resultados dos modelos de vários países.

As projeções dos cenários da mudança do clima são derivadas dos vários modelos. Essas projeções têm como base diferentes cenários de emissão de gases do efeito estufa, dependendo do grau de desenvolvimento econômico do país, bem como da sua cultura de sustentabilidade, por exemplo. De acordo com o IPCC [6], os cenários climáticos e socioeconômicos representativos de tendências (Representative Concentration Pathways) (RCPs) consideram uma forçante devido aos gases do efeito estufa, aerossóis e gases quimicamente ativos, bem como o uso da terra. Os RCPs são especificados com um número que acompanha a sigla RCP, que é medido em $\mathrm{W} / \mathrm{m}^{2}$. Por exemplo, o RCP 8.5 indica altas emissões; o RCP 6.0, intermediárias; o RCP 4.5, intermediáriasbaixas; e o RCP 2.6, baixas. O valor da forçante total atual é $2,29 \mathrm{~W} / \mathrm{m}^{2}$ [6].

Antes de prosseguirmos, ressaltemos que, neste texto, a discussão dos modelos climáticos, mais adiante, terá o objetivo de instrumentalizar a analogia entre o nosso organismo e o sistema climático ou, simplesmente, entre corpo humano e Terra, tal que nosso foco está na atribuição de uma temperatura para sistemas fora do equilíbrio termodinâmico, o que remete a temperatura global média do planeta. Nesse sentido, a Figura 1 subsidia o entendimento de significativa parte da controvérsia

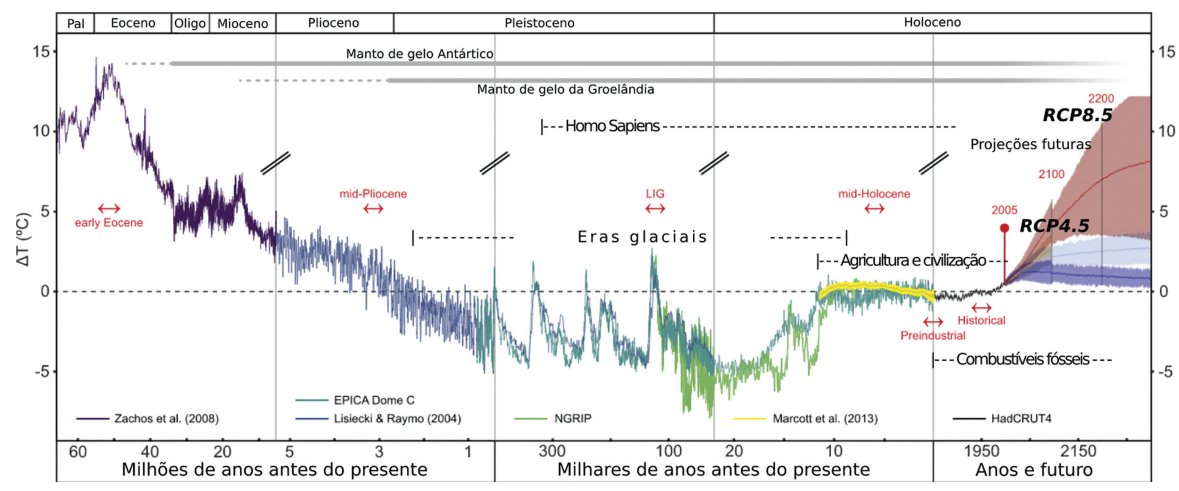

Figura 1: Anomalias de temperatura ao longo da história geológica da Terra, tendo como base o período entre 1961 e 1990. Fonte: Adaptada da Ref. [15]. 
do aquecimento global e da complexidade do sistema climático 6

O gráfico representa a evolução das anomalias de temperatura da Terra ao longo de mais de 60 milhões de anos, passando por variações significativas. Há cerca de 50 milhões de anos (no Eoceno), as temperaturas eram quase $15^{\circ} \mathrm{C}$ mais altas do que as do período de referência (tomada entre 1961 e 1990), aproximadamente. Já as eras glaciais foram períodos caracterizados por temperaturas extremamente baixas na história geológica da Terra.

Dessa forma, devido ao aumento da concentração de gases do efeito estufa na atmosfera, a uma forçante radiativa positiva $\left(2,29 \mathrm{~W} / \mathrm{m}^{2}\right)$, ao aquecimento observado e ao próprio entendimento sobre o sistema climático, "a influência humana é clara" [6, p. 15]. Nesse sentido, o gráfico também nos alerta sobre dois possíveis cenários RCPs que são preocupantes, um que é projetado pelo RCP 4.5 e outro pelo RCP 8.5. Notemos que o primeiro deles remete o estado climático do plioceno médio, enquanto que, para o segundo cenário, o eoceno emerge como o melhor análogo [15].

O cenário RCP 8.5 é perturbador porque uma mudança que poderia acontecer em milhares de anos pode vir a ocorrer em cerca de um século ou pouco mais. Somado a esse elemento, precisamos considerar que o homo sapiens surgiu há cerca de 300 mil anos, quando as temperaturas não eram tão diferentes das atuais. Temos, então, a questão: a espécie humana poderia sobreviver em uma realidade com temperaturas tão altas?

Em especial, observemos que, a partir dos últimos milênios das eras glaciais, o clima da Terra evoluiu para um estado de equilíbrio dinâmico, que foi estabelecido há cerca de 10 mil anos. Esse estado pode ser caracterizado por uma faixa estável de temperatura que propiciou o desenvolvimento da agricultura e da civilização moderna (faixa amarela), que corresponde ao holoceno médio; hoje, a temperatura observada da Terra é de $288 \mathrm{~K} 6$.

A emergência desse estado é um indicativo de autoorganização do sistema. Essa robustez do clima persiste até a Primeira Revolução Industrial, que terminou em 1850, quando teve início a emissão de combustíveis fósseis na atmosfera. Frisemos que a concentração de $\mathrm{CO}_{2}$ aumentou cerca de $40 \%$ desde a época préindustrial e, entre meados da década de 1960 e 2010, foi de 320 ppm a $390 \mathrm{ppm}$, aproximadamente 6]. Somado a esse fator, a atmosfera contém cerca de $0,039 \%$ de gás carbônico. Notamos, então, que um aumento aparentemente pequeno da concentração desse gás na atmosfera e as suas implicações drásticas enfatizam a não linearidade do sistema climático.

Em resumo, a Figura 1 ilustra algumas características de sistemas físicos complexos. Em particular, destacamos a evolução do clima terrestre para um estado

6 Parte das adaptações na Figura 1 foi inspirada no seminário da professora e pesquisadora Ilana Wainer, disponível no link: https://www.youtube.com/watch?v=HjDij8R1l60\&t=2322s de quasi-equilíbrio. Nesse período, de cerca de 10 mil anos, o estado de equilíbrio parece ser suficientemente robusto, resistindo a variações dos subcomponentes e permanecendo dentro uma faixa de temperatura. $\mathrm{O}$ estabelecimento desse estado em um sistema complexo e aberto, associado à manutenção dessa temperatura, tem analogia com o corpo humano.

Na próxima seção, exploramos essa analogia cujas possibilidades didáticas permitem explorar não apenas as discussões sobre o clima e os modelos climáticos, mas também características da complexidade em sistemas físicos, em geral.

\section{A Natureza Complexa do Corpo Humano}

O sistema climático tem uma natureza complexa em dois sentidos. De um lado, é um sistema composto por diversos subsistemas cujas escalas temporais vão de segundos a bilhões de anos, enquanto as espaciais vão da ordem molecular à planetária; nesse caso, a complexidade tem o sentido de complicado. De outro lado, e de forma tão relevante quanto, é um sistema caracterizado por interações não lineares cujas intensidades dos estímulos e perturbações não são proporcionais aos seus efeitos. Ademais, a evolução temporal não determinística do clima é marcada por propriedades e estados globais emergentes, ou seja, por estados de quasi-equilíbrio cuja robustez é reflexo de mecanismos de restauração e feedback, que são características intrínsecas da complexidade. Essa natureza é aceitável, porém não é de fácil compreensão. Nesse sentido, ela pode ser discutida a partir de um sistema que também nos é corriqueiro, o corpo humano.

O corpo humano é um conjunto de sistemas, também complexos, cujas interações o levam a progredir para um estado de equilíbrio, que nós reconhecemos como saudável. Analogamente à Terra, diversos subsistemas atuam na dinâmica do sistema e contribuem para a preservação desse estado, que é mantido por uma base neural complexa: o termostato hipotalâmico. Segundo Laganá, Fato e Araújo [16]:

"A regulação da temperatura corporal [...] envolve intrincados mecanismos de vários sistemas do organismo a partir de transferências químicas e físicas de calor, a saber: controle fisiológico (neurológico) e o comportamental; equilíbrio entre produção e perda de calor; sistema isolador do corpo; regulação térmica da pele; secreção das glândulas sudoríparas; aclimatação; receptores termossensíveis e sensibilidade térmica; sistema vasomotor" [16].7

Os mecanismos que atuam na regulação da temperatura corporal sofrem influências de natureza interna

\footnotetext{
7 Grifos das autoras.
} 
(anomalia de algum subsistema do organismo) e externa (prática de atividades físicas, emoção, ambiente, medicação, etc.). Como no caso da Terra, as anomalias de temperatura do corpo, isto é, diferenças em relação ao estado de equilíbrio, indicam que algo não está bem com o organismo. As anomalias podem implicar a perda de robustez e a migração do sistema para um outro estado que não seja o de equilíbrio, como o febril. Particularmente, esse estado pode colapsar devido à pequenas, porém significativas variações em alguns dos subsistemas do corpo humano. Essa característica, cujos efeitos não são proporcionais às intensidades das causas, é reconhecida como não linearidade. Assim, através de mecanismos de controle e regulação, o corpo busca restabelecer o estado de equilíbrio, processo que depende, de maneira não linear, das variações dos subsistemas e da capacidade do sistema de se autorregular.

Tal como o sistema climático, o corpo humano é um sistema aberto que sofre influências internas e externas. Em ambos os casos, a noção de temperatura não é a de uma grandeza associada ao equilíbrio térmico com o meio; os dois sistemas são caracterizados por um campo de temperaturas. Porém, existem pontos específicos onde a temperatura corporal é medida, os quais são suficientemente precisos para indicação ou não de febre ou outra anomalia. Dessa forma, não é necessário calcular uma média de temperaturas de cada componente ou subsistema do nosso organismo, de forma literal, pois existem vias de mensuração que são significativas e/ou viáveis (axila, boca, tímpano, reto, fronte) 8 Em outras palavras, as características emergentes do corpo humano nos mostram que um conjunto de medidas de temperatura de diferentes partes do corpo humano não implica em um maior conhecimento sobre o estado de saúde da pessoa, desde que a escolha da via de mensuração seja criteriosa.

No caso da Terra, os oceanos nas regiões dos polos, por exemplo, fornecem informações significativas sobre a temperatura e "saúde" do planeta. Assim, são inócuas as críticas que apontam a falta de uma distribuição de estações de medidas mais abrangentes, uma vez que os modelos climáticos desenvolvidos se mostram relevantes e suficientes para o entendimento da dinâmica do clima, pois trabalham com pesos diversos para cada região/local. Logo, os modelos climáticos operam de forma consciente para que sejam levadas em conta as medidas de temperatura dos locais mais relevantes para os mecanismos regulação do planeta. Em outras palavras, o objetivo de fixação de uma temperatura média calculada a partir do maior número possível de localidades, à la mercadores da dúvida, indica uma visão linear e despreza a complexidade do sistema climático.

\footnotetext{
8 A temperatura central ou interna do corpo, por definição, é a temperatura da artéria pulmonar [16]. Para fins práticos, explicam as autoras, a temperatura retal é considerada a temperatura de referência, pois ela tem a temperatura mais próxima da temperatura central.
}

Na próxima seção, a partir de uma analogia entre o corpo humano e a Terra, propomos uma abordagem didática que objetiva contemplar algumas características da complexidade. Essa discussão visa a sala de aula.

\section{O Corpo Humano Como Modelo Didático Análogo}

A analogia proposta nessa seção busca apontar potencialidades didáticas para o uso do corpo humano como modelo problematizador de questões acerca da complexidade do sistema climático e da complexidade encerrada pelos modelos climáticos. Pela proximidade e vivência, a exploração conceitual da complexidade no corpo humano e a análise comparativa com o sistema climático podem auxiliar no entendimento de ambos os sistemas e também da própria complexidade em si.

O corpo humano e o sistema climático são sistemas abertos, constituídos de um grande número de subsistemas e componentes independentes que interagem de forma não linear e que se auto-organizam. Dessa dinâmica, emergem estados de quasi-equilíbrio extremamente robustos, que resistem a perturbações externas através de mecanismos de autorregulação.

Como foco na sala de aula, entendemos que esse debate deve ser centrado em conceitos, que são potencializados com a análise da evolução temporal da temperatura global do planeta. Na Figura 11 como já avaliamos, percebemos que um estado de equilíbrio dinâmico emerge após variações de temperatura que chegaram a mais de $25^{\circ} \mathrm{C}$. Esse estado tem se sustentado por toda a história da humanidade; a sua manutenção ao longo de boa parte dessa história explicita a sua robustez e é análoga à estabilização da temperatura saudável do corpo humano.

Quando alguma anomalia acomete o sistema, o estado de equilíbrio pode ser desconfigurado. Por exemplo, pequenos distúrbios nos sistemas do corpo humano podem levar a um colapso. Por sua vez, a conservação do estado de equilíbrio dinâmico da Terra está sendo ameaçada. Devido ao aumento da concentração dos gases do efeito estufa na atmosfera, em particular do dióxido de carbono, o sistema climático tem apresentado, nas últimas décadas, sintomas preocupantes para a humanidade, fato que não pode ser explicado somente pelos fatores naturais [6]. Por um lado, o $\mathrm{CO}_{2}$ representa uma parcela de apenas $0.039 \%$ dos gases da atmosfera; por outro, suas consequências se dão em grandes escalas e podem levar o planeta a condições extremas para a manutenção da vida como a temos hoje. Ou seja, um efeito de pequena intensidade pode ter consequências funestas. Essa discussão caracteriza a não linearidade no sistema climático.

Em resumo, a analogia didática entre corpo humano e sistema climático nos parece viável para discutir conceitos da complexidade em sala de aula. As noções de auto-organização, emergência, não linearidade, 
múltiplas escalas e mecanismos de feedback são alguns dos conceitos da complexidade que podem ser explorados por essa analogia, instrumentalizando a compreensão da física de ambos os sistemas. Em particular, a Figura 1 abrange diversos aspectos de sistemas físicos complexos e pode ser utilizada como instrumento didático.

\section{Considerações Finais}

Neste artigo, procuramos explorar a complexidade de sistemas físicos no contexto da temática do aquecimento global. Discutimos a ideia de temperatura global e como a sua compreensão exige a consideração da complexidade da Terra, tal que críticas ao estilo mercadores da dúvida não fazem sentido. Caracterizamos o sistema climático como um sistema complexo e analisamos como os modelos climáticos levam em conta aspectos de sua complexidade. Ao caracterizar o corpo humano como um sistema complexo, instrumentalizamos uma analogia que pode ser empregada em sala de aula para o ensino de noções da complexidade do sistema climático, bem como para o ensino da física de ambos os modelos de forma individual.

Conceitualmente, nossa discussão foi centrada na ideia de temperatura global e sua evolução histórica, a qual viabiliza a abordagem de algumas características complexas do sistema climático a partir da analogia com o corpo humano: não linearidade, robustez, auto-organização e emergência. Essas características de sistemas complexos se fazem presentes nas reflexões de Caramello [17], por exemplo. Alertemos que a abordagem didática sugerida neste artigo pode e deve ser aprofundada.

Outrossim, a analogia também pode ser considerada de forma ilustrativa. Por exemplo, ao se sugerir um paralelo entre o consenso científico acerca do aquecimento global e a convergência de diferentes diagnósticos clínicos apontados por médicos distintos com base em observações e investigações múltiplas a respeito de um paciente. Há várias outras formas de se propor essa analogia ilustrativa, as quais não foram discutidas neste texto.

Relatemos também uma experiência positiva com alunos da terceira série do ensino médio de uma instituição federal de ensino, tanto em termos de engajamento quanto de aprendizado de conceitos. Negativamente, percebemos a dificuldade inicial que os estudantes tiveram em lidar com a Figura 1, especialmente por levar em conta escalas de tempo que vão de anos a milhões de anos. De fato, a proposição de um ensino dessa natureza exige um grande esforço do professor, especialmente quanto ao entendimento da ciência subjacente ao tema e em relação ao aprendizado dos alunos e suas dificuldades.

Destaquemos, por fim, que as mudanças climáticas e o aquecimento global são temas atuais e relevantes para o ensino da física. Em geral, pesquisas e propostas didáticas da literatura que envolvem essa temática focalizam as análises socio-políticas e ambientais. Logo, tivemos o objetivo de sugerir uma abordagem que dialogue com conceitos da física da termodinâmica, algo factível para estudantes, inclusive do ensino fundamental, com foco em noções da complexidade de sistemas físicos, objeto deste número especial. Nesse sentido, esperamos que este texto também possa subsidiar futuras investigações da área, bem como contribuir para uma maior aproximação entre as pesquisas em educação em ciências e em ensino de física e o professor que está na sala de aula.

\section{Agradecimentos}

Agradecemos ao(à) parecerista pelas criteriosas e valiosas sugestões, que contribuíram significativamente para a melhoria deste texto.

\section{Referências}

[1] N. Oreskes e E. Conway, Merchants of Doubt: How a Handful of Scientists Obscured the Truth on Issues from Tobacco Smoke to Global Warming (Bloomsbury Press, London, 2010), 369 p.

[2] D.A. Reis e L.F. Silva, Ciênc. \& Ed. 22, 145 (2016).

[3] A. Pina, L.F. Silva e Z.T. Oliveira Júnior, Cad. Bras. Ens. Fís. 27, 449 (2010).

[4] D.A. Magalhães, Rev. Bras. Ens. Fís. 36, 4502 (2014).

[5] D.A. Reis, L.F. Silva e N. Figueiredo, Rev. Ens. 17, 535 (2015).

[6] IPCC, Climate Change 2013: The Physical Science Basis. Contribution of Working Group I to the Fifth Assessment Report of the Intergovernmental Panel on Climate Change (Cambridge University Press, Cambridge and New York, 2013), 1535 p.

[7] C. Essex, R. Mckitrick e B. Andresen, Journ. Non-Eq. Therm. 32, 1 (2007).

[8] R. Gallagher e T. Appenzeller, Sc. 284, 79 (1999).

[9] D. Rind, Sc. 284, 105 (1999).

[10] Y. Holovatch, R. Kenna e S. Thurner, Eur. Journ. Phys. 38, 023002 (2017).

[11] G.A. Schmidt, Phys. Tod. 60, 72 (2007).

[12] G. Flato, J. Marotzke, B. Abiodun, P. Braconnot, S.C. Chou, W. Collins, P. Cox, F. Driouech, S. Emori, V. Eyring et al., em: Climate Change 2013: The Physical Science Basis. Contribution of Working Group I to the Fifth Assessment Report of the Intergovernmental Panel on Climate Change, editado por T.F. Stocker, D. Qin, G.K. Plattner, M. Tignor, S.K. Allen, J. Boschung, A. Nauels, Y. Xia, V. Bex e P.M. Midgley (Cambridge University Press, Cambridge and New York, 2013).

[13] J.E. Hansen e M. Sato, em: Climate Change Inferences from Paleoclimate and Regional Aspects, editado por A. Berger, F. Mesinger e D. Sijacki (Springer, Vienna, 2012).

[14] A. Berger, em: Climate Change Inferences from Paleoclimate and Regional Aspects, editado por A. Berger, F. Mesinger e D. Sijacki (Springer, Vienna, 2012). 
[15] K.D. Burke, J.W. Williams, M.A. Chandler, A.M Haywood, D.J. Lunt e B.L. Otto-Bliesner, Proc. Nat. Ac. Sc. 115, 13288 (2018).

[16] M.T.C. Laganá, A.C.M. Faro e T.L. Araújo, Rev. Esc. Enf. USP 26, 173 (1992).

[17] G.W. Caramello, Aspectos da complexidade: contribuições da Física para a compreensão do tema ambiental. Tese de Doutorado, Universidade de São Paulo, São Paulo (2012). 